repair. Before the operation, he received 6 units of platelets and intravenous desmopressin at $0.3 \mu \mathrm{g} / \mathrm{kg}$ every 2 hours for 4 doses. He was discharged on postoperative day 8 without complications. ${ }^{5}$

Our patient underwent a careful preoperative hematologic workup to rule out antiplatelet antibodies and to match donor platelets for compatibility. She received 2 units of platelets just before the operation and was then monitored carefully for clinical and laboratory signs of coagulopathy. Extra attention was also paid to precise surgical technique. The VerifyNow IIb/IIIa assay (Accumetrics, Inc, San Diego, Calif), typically used to assess levels of functioning platelets in patients treated with glycoprotein IIb/IIIa inhibitors such as abciximab or eptifibatide, was used perioperatively to monitor levels of properly functioning platelets. ${ }^{6}$

We conclude that patients with Glanzmann thrombasthenia are able to undergo heart surgery despite their bleeding diathesis, as long as care is taken in proper preoperative workup to prepare for and avoid potential complications. This was accomplished in our patient through close collaboration of hematology, the blood bank, and the cardiopulmonary bypass team.

\section{References}

1. George JN, Caen JP, Nurden AT. Glanzmann's thrombasthenia: the spectrum of clinical disease. Blood. 1990;75:1383-5.

2. Hennewig U, Laws HJ, Eisert S, Gobel U. Bleeding and surgery in children with Glanzmann thrombasthenia with and without the use of recombinant factor VIIa Klin Padiatr. 2005;217:365-701.

3. Connor P, Khair K, Liesner R, Amrolia P, Veys P, Ancliff P, et al. Stem cell transplantation for children with Glanzmann thrombasthenia. Br J Haematol. 2008;140: 568-71.

4. Ryckman JG, Hall S, Serra J. Coronary artery bypass grafting in a patient with Glanzmann's thrombasthenia. J Card Surg. 2005;20:555-6.

5. Yilmaz BT, Alioglu B, Ozyurek E, Akay HT, Mercan S, Ozbek N. Successful use of recombinant factor VIIa (NovoSeven) during cardiac surgery in a pediatric patient with Glanzmann thrombasthenia. Pediatr Cardiol. 2005;26:843-5.

6. van Werkum JW, Harmsze AM, Elsenberg EH, Bouman HJ, ten Berg JM, Hackeng CM. The use of the VerifyNow system to monitor antiplatelet therapy: a review of current evidence. Platelets. 2008;19:479-88.

\title{
Surviving a transfixing cardiac injury caused by a stingray barb
}

\author{
Michael W. Parra, MD, ${ }^{\mathrm{a}}$ Eugene N. Costantini, MD, FACS, ${ }^{\mathrm{b}}$ Edgar B. Rodas, MD, ${ }^{\mathrm{a}}$ Pedro J. Gonzalez, MD, ${ }^{\mathrm{a}}$ \\ Omar J. Salamen, DDS, ${ }^{c}$ Joseph D. Catino, MD, ${ }^{\mathrm{a}}$ Paul M. Taber, RN, BSN, ${ }^{\mathrm{a}}$ and Ivan Puente, MD, FACS, ${ }^{\mathrm{a}}$ \\ Fort Lauderdale, Fla
}

Stingray injuries have a traumatic component (puncture) and a toxic component (envenomation). Envenomation is generally not lethal but causes intense pain and significant local tissue necrosis. Rare puncture injuries to the thorax or abdomen can cause serious injuries and death. ${ }^{1}$ The following is a description of what we believe to be the first reported survivor of a transfixing cardiac injury caused by a stingray barb.

\section{CLINICAL SUMMARY}

An 81-year-old man was driving his boat when a spotted eagle stingray leaped out of the water, struck his torso, and landed on his lap. The patient was inadvertently stung

\footnotetext{
From the Divisions of Trauma and Critical Care ${ }^{\mathrm{a}}$ and Thoracic and Cardiovascular Surgery, ${ }^{\mathrm{b}}$ Broward General Medical Center; and the Division of Oral Maxillofacial Surgery, ${ }^{\mathrm{c}}$ NOVA Southeastern University, Fort Lauderdale, Fla.

Disclosures: None.

Received for publication Jan 23, 2009; revisions received Feb 12, 2009; accepted for publication Feb 24, 2009; available ahead of print June 1, 2009.

Address for reprints: Michael W. Parra, MD, Division of Trauma Critical Care, Broward General Medical Center/Level I Trauma Center, 1600 S Andrews Ave, Fort Lauderdale, FL 33316 (E-mail: michaelwparra@yahoo.com).

J Thorac Cardiovasc Surg 2010;139:e115-6 0022-5223/\$36.00

Copyright (c) 2010 Published by Elsevier Inc. on behalf of The American Association for Thoracic Surgery

doi:10.1016/j.jtcvs.2009.02.052
}

with the barb in his left chest and was immediately transported to a nearby level II trauma center by emergency medical personnel. Physical examination revealed a 2-mm irregular laceration to the anterior left chest wall just medial and slightly inferior to the corresponding nipple. A computed tomographic scan of the chest showed a $5 \%$ left pneumothorax and a $2-\mathrm{cm}$ linear foreign body penetrating the anterior chest wall. A left anterior thoracotomy and a pericardiotomy were performed in the operating room. After recognizing that the foreign body was intracardiac, the 2 ventricular wall defects were closed with pericardial pledgets for hemorrhage control, and the patient was transferred to our institution. An echocardiogram showed the barb sitting across both the left and right ventricles (Figure 1). The patient was returned to the operating room, and through a median sternotomy, he was started on cardiopulmonary bypass. The right atrium was accessed, and the stingray barb was visualized by means of gentle traction of the posterior leaflet of the tricuspid valve (Figure 2). The barb was removed in an antegrade fashion, pulling it through the free wall of the right ventricle to prevent the barb from causing any additional trauma. The ventricular septum and the right ventricular free wall defects were closed with pledgeted Prolene sutures 


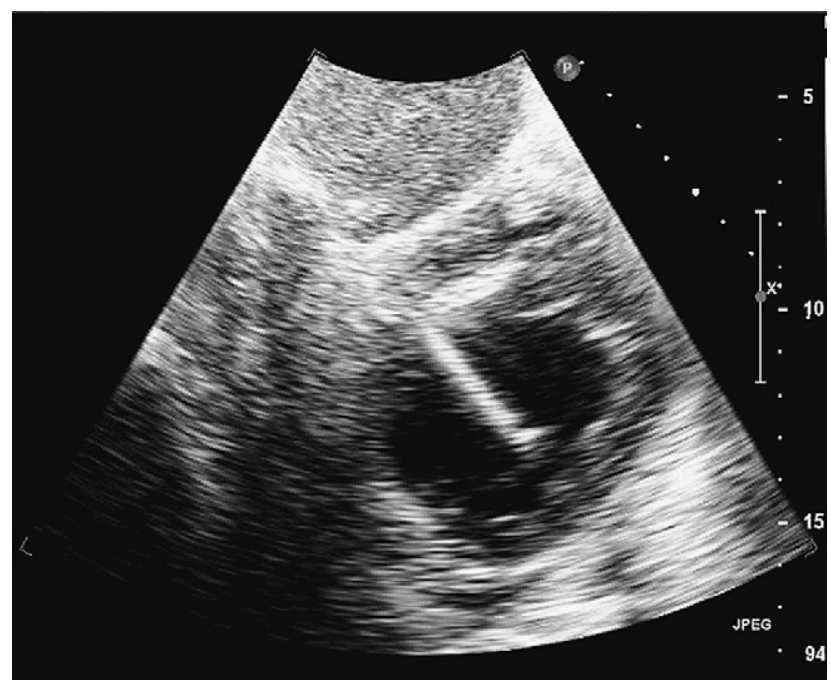

FIGURE 1. Echocardiogram revealing the transfixed cardiac stingray barb.

(Ethicon, Inc, Somerville, NJ). The right atrium was then closed, and the patient was weaned from cardiopulmonary bypass.

On postoperative day 1 , the patient presented with an acute onset of hemodynamic instability, distended abdomen, and a significant decrease in hemoglobin level. A bedside abdominal ultrasonographic scan revealed free intraabdominal fluid. An exploratory laparotomy confirmed hemoperitoneum caused by a splenic injury. A splenectomy was performed, and the abdomen was left open to avoid the possibility of a subsequent postoperative abdominal compartment syndrome. The abdomen was closed 48 hours later. The patient eventually had a full recovery and was discharged from the hospital 2 months later.

\section{DISCUSSION}

Penetrating cardiac injuries can be caused by a multiplicity of sharp objects, ${ }^{2}$ and they continue to be challenging cases for trauma surgeons. Moreover, if the foreign object remains embedded in the heart, it creates an additional hardship in management. Penetrating injuries to the heart caused by a stingray barb can be fatal. An example of such is the well-known case of Steve Irwin, the "crocodile hunter," who had been filming an underwater series off the north shore of Australia when he was stung in the chest by a stingray. Irwin pulled the barb immediately and died within minutes after the foreign body was removed. To date, there have been 2 previously documented survivors of cardiac injuries caused by stingray barbs. ${ }^{3,4}$ However, these were puncture wounds that did not transfix the cardiac chambers.

As described above, our case was clearly a complex cardiac injury. When victims survive the prehospital period, such injuries carry a high mortality rate of up to $53 \%$, as observed in a 20 -year retrospective review by Wall and colleagues. ${ }^{5}$ Despite the complexity of most of these cardiac

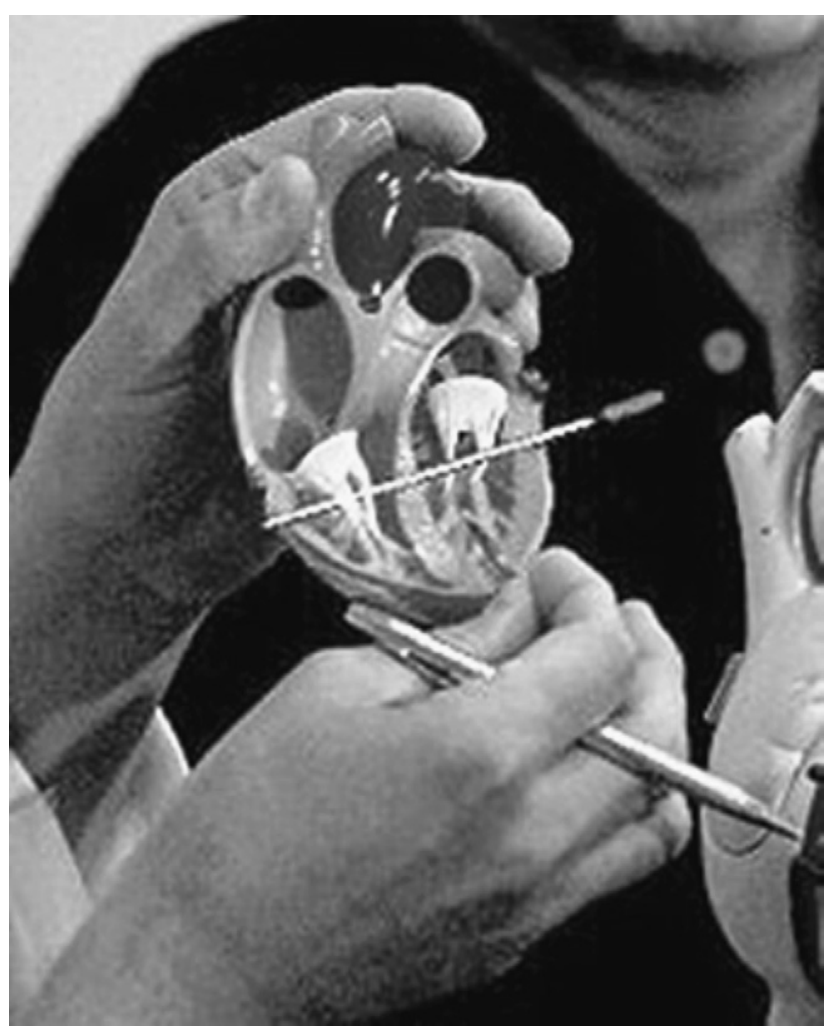

FIGURE 2. Diagram depicting the intracardiac course of the stingray barb.

injuries, the need for emergency cardiopulmonary bypass is rare $(<1 \%) .{ }^{5}$ However, emergency cardiopulmonary bypass remains a noble method for definitive treatment when intricate cardiac injuries are identified, as evidenced in our patient.

Of additional interest, after the successful surgical treatment of this complex cardiac injury, this case was further complicated by the late recognition of a concomitant blunt splenic injury. This injury became apparent as a delayed hemoperitoneum after heparinization was required for cardiopulmonary bypass, thus underlining the need to maintain high levels of vigilance for other potentially life-threatening injuries when the mechanism warrants it.

To our knowledge, the case presented is the first and only reported survivor of a transfixing cardiac injury caused by a stingray barb. Our success was largely due to an integrated trauma system, with rapid transport by our prehospital providers, initial stabilization by the surgical staff at the receiving facility, and expeditious referral to the regional trauma center for definitive care.

\section{References}

1. Meyer PK. Stingray injuries. Wilderness Environ Med. 1997;8:178.

2. Asensio JA, Soto SN, Forno W. Penetrating cardiac injuries: a complex challenge. Injury. 2001;32:533-43.

3. Weiss BF, Wolfenden HD. Survivor of a stingray injury to the heart. Med J Aust. 2001;175:33-4.

4. Ronka EKF, Roe WF. Cardiac wound caused by the spine of the stingray. Mil Surgeon. 1945;97:135-6.

5. Wall MJ, Mattox KL, Chen C. Acute management of complex cardiac injuries. J Trauma. 1997;42:905-12. 